\title{
Effects of Sodium Salts of Lyotropic Anions on Low-Temperature, Ordered Lipid
}

\section{Monolayers}

M. Christoforou ${ }^{1}$, E. Leontidis ${ }^{1, *}$, and G. Brezesinski ${ }^{2}$

1: Department of Chemistry, University of Cyprus, Nicosia 1678, Cyprus

2: Max Planck Institute of Colloids and Interfaces, D-14424 Potsdam-Golm, Germany

*: To whom all correspondence should be addressed

Tel. +357 22 892767, FAX +357 22 895452, Email: psleon@ucy.ac.cy

Revised Version Submitted to the Journal of Physical Chemistry

25 November 2012

Keywords: Phospholipid monolayers, ion-specific effects, Hofmeister series, dipalmitoyl phosphatidylcholine, temperature effect. 


\section{$\underline{\text { Abstract }}$}

Electrolytes are known to impart considerable disorder to lipid assemblies, including monolayers at the air-water interface, bilayers and vesicles. In the present work we have investigated the disordering effect of sodium salts of monovalent anions that span the lyotropic series on the monolayers of 1,2-dipalmitoyl-sn-glycero-phosphocholine (DPPC) at $12{ }^{\circ} \mathrm{C}$. Pressure-area isotherms, Brewster-Angle Microscopy (BAM), grazing-incidence Xray diffraction (GIXD), and infrared absorption-reflection spectroscopy (IRRAS) were used to investigate in complementary ways the salt effects on lipid monolayers. At $12^{\circ} \mathrm{C}$ these effects were found to be quite dramatic, a major finding being that the liquid-expanded phase, which is not present at this temperature on a pure water subphase, reappears and dominates in the presence of electrolytes. Salts expand the monolayer, destroy the ordered phase that exists at zero pressure, and affect the ordering of the lipid chains and their tilt angle in the liquid condensed phase. Finally, very chaotropic anions force DPPC lipids to adopt an untilted conformation in the condensed phase, an unprecedented finding for non-mixed Langmuir monolayers of this phospholipid. A distinctly different behavior of very chaotropic anions from that of normal chaotropic ones thus emerges. The effect of the former is not just a limited perturbation of the lipid assembly, but a major disruption of the structure, which arises from competition between the lipids and the ions for interfacial sites. 


\section{Introduction}

Ion-specific effects have been found in a very large variety of systems and phenomena, and ionic specificity usually follows the Hofmeister or lyotropic series of ions. ${ }^{1-17}$ In the last decade, the mechanism of specific ionic action in several systems has been considerably clarified through intensive research effort in this area (see recent reviews, journal issues, and books on the topic $\left.{ }^{6-18}\right)$. It has been established that specific ion action involves a fine balance of interactions between water (the usual solvent), ions, and a solute or a surface, depending on the system. There is still considerable discussion however about the relative importance of individual interactions in many systems, while specific ion action is so rich and so farreaching that the field is still open for discovery of new phenomena.

For some time we have been using Langmuir monolayers of zwitterionic phospholipids as model systems to understand specific anion effects in physicochemical and biological systems. ${ }^{1-5}$ Our monolayer work focuses primarily on anions. We formerly worked at room temperature $\left(22^{\circ} \mathrm{C}\right)$, and used a variety of simple sodium salts and the classical phospholipid 1,2-dipalmitoyl-sn-glycero-phosphocholine (DPPC). It was found that the ion-lipid interaction cannot be described as "binding", but is satisfactorily described as partitioning of the ions into the lipid monolayer. ${ }^{3,4,14}$ The ions create disorder, favoring the liquid-expanded phase over the liquid condensed phase. ${ }^{1}$ The partitioning chemical potentials of several anions between DPPC monolayers and bulk water were evaluated with an appropriate electrostatic model. They were found to favor interfacial solubilization for the chaotropic anions of the lyotropic series. They were also found dependent on the size of the ions in a rather complex way, reflecting phenomena related to both ion-cavity creation and ionic solvation that are involved in the partitioning process. ${ }^{3,4,14}$ A useful extension of this work would be to extract ionic partitioning chemical potentials at several temperatures, to obtain the enthalpic and entropic contributions to the partitioning process. However, at temperatures below ambient 
DPPC monolayers become gradually more ordered, and at a low enough temperatures (below roughly $15{ }^{\circ} \mathrm{C}$ ) the LE-LC transition disappears. ${ }^{19-22}$ In Figure 1 we present our own data on the evolution of DPPC monolayer isotherms with temperature, in order to show more clearly the temperature at which the LE-LC plateau vanishes. Our results are essentially in agreement with those in the literature, and demonstrate the progressive monolayer ordering with decreasing temperature.

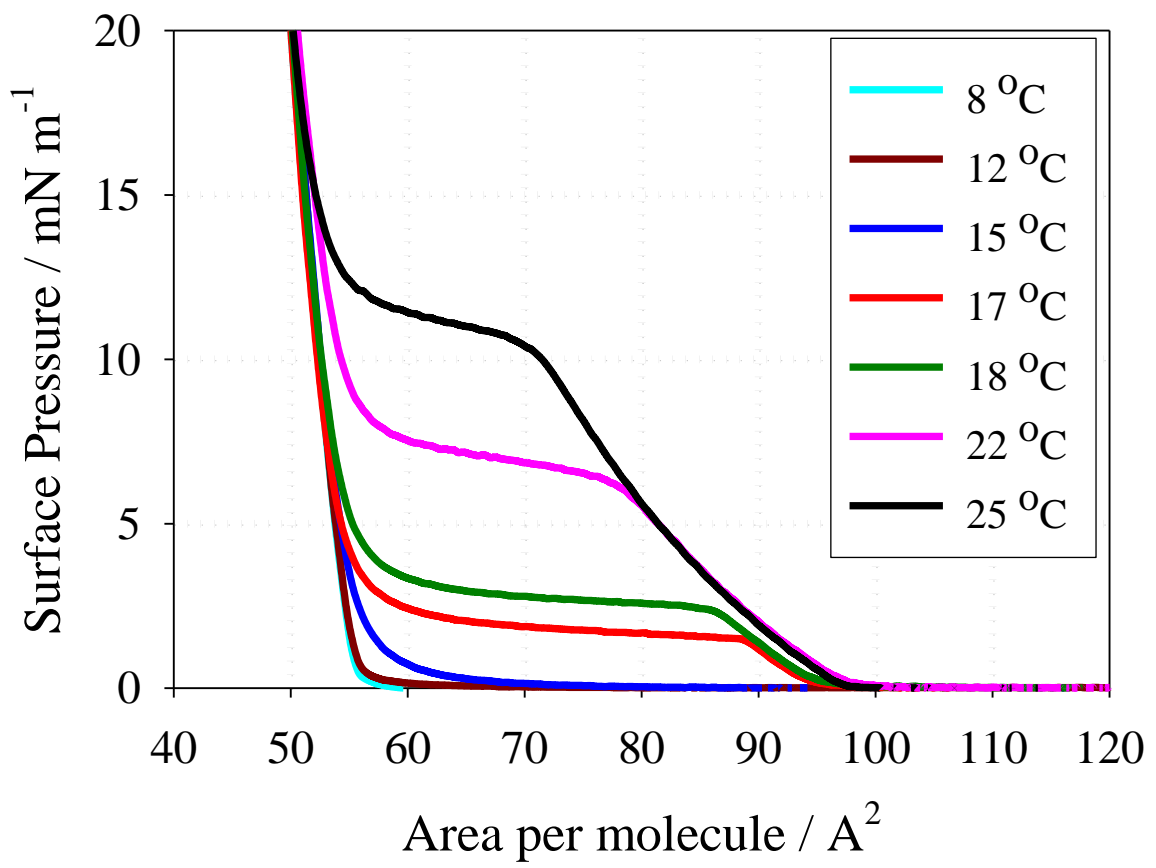

Figure 1: Pressure-area isotherms of DPPC monolayers on water as a function of temperature in the range $8-25^{\circ} \mathrm{C}$.

Since sodium salts were found to interact quite strongly with zwitterionic monolayers imparting considerable disorder at room temperature, it is useful to study the effects of these salts on DPPC monolayers at lower temperatures. The question we wish to address here is to what extent anions of the lyotropic series can counteract the ordering effect of temperature observed in Figure 1. Similar phenomena have been observed before in the study of lipid bilayer phase transitions, where anions have been found to affect the gel-liquid transition 
temperatures of phospholipid bilayers and vesicles in ion-specific ways. ${ }^{23-27}$ The literature on salt effects on lipid bilayers consistently shows that chaotropic anions disrupt the order, increase the fluidity, and reduce the gel to liquid transition temperature. Cations, especially multivalent cations, may in fact change the headgroup conformation of DPPC in bilayers, as observed with NMR spectroscopy, ${ }^{28-31}$ while the analogous effect for anions is thought to be smaller. $^{32,33}$ Investigations of the interplay of anionic and temperature effects in lipid monolayers have not been performed in a systematic way to date. This is rather strange as monolayers offer some unique advantages, as pointed out in our previous work, ${ }^{1-5,14}$ since they exhibit a rich structural and phase behavior that can be probed both with macroscopic measurements (microscopy, surface pressure and surface potential isotherms) and with advanced spectroscopic and scattering methods.

In the present work we examine the effects of sodium salts of selected anions of the lyotropic series on DPPC Langmuir monolayers at $12{ }^{\circ} \mathrm{C}$. As seen in Figure 1, the monolayer is quite ordered at this temperature, and does not exhibit the LE-LC phase coexistence, which is the major feature of isotherms obtained at higher temperatures. We have used $\mathrm{NaCl}, \mathrm{NaBr}$, $\mathrm{NaNO}_{3}, \mathrm{NaSCN}, \mathrm{NaClO}_{4}, \mathrm{NaPF}_{6}$, and sodium tetraphenylborate (NaTPB) as electrolytes, to span the greatest possible range of the lyotropic series. Chloride was found to have a very marginal interaction with DPPC monolayers at room temperature, ${ }^{1-4}$ and is in fact found in many phenomena to exhibit "indifferent" behavior and to be at the border between kosmotropic and chaotropic anions. ${ }^{6-8,13-15}$ At the other end of the scale tetraphenylborate is not usually considered to belong to the lyotropic series. It is a hydrophobic, surface-active anion, which has been shown to interact very strongly with zwitterionic lipids at the waterheptane interface, ${ }^{34}$ and in vesicles, ${ }^{35}$ to intercalate between lipids in charged ${ }^{36}$ or zwitterionic $^{37,38}$ monolayers, and to strongly stick to hard hydrophobic surfaces. ${ }^{39}$ 
Besides using pressure-area isotherms to observe anion effects on the macroscopic behavior of DPPC monolayers at $12{ }^{\circ} \mathrm{C}$, we have examined the phase behavior with Brewster angle microscopy (mesoscopic $(\mu \mathrm{m})$ scale), grazing incidence X-ray diffraction (GIXD, microscopic (nm) scale) and infrared reflection-absorption spectroscopy (IRRAS, bond ( $\AA$ ) scale). The broad range of length scales, over which information can be easily collected with complementary methods, is a unique advantage of Langmuir monolayers as model systems. This multi-length-scale examination will allow us to extract safe conclusions about ionphopsholipid monolayer interactions at temperatures lower than room temperature.

\section{Materials and Methods}

\subsection{Materials}

The phospholipid 1,2-dipalmitoyl-sn-glycero-phosphocholine (DPPC) was obtained from Avanti Polar Lipids, and used without further purification. Chloroform (Acros Organics, 99.9 \%) was used as a solvent to prepare $1 \mathrm{mM}$ solutions of DPPC. $\mathrm{NaCl}, \mathrm{NaBr}, \mathrm{NaNO}_{3}, \mathrm{NaI}$, $\mathrm{NaClO}_{4} \cdot \mathrm{H}_{2} \mathrm{O}$ were purchased from Merck (purity $>99 \%$ ). NaSCN was also from Merck (purity > $98.5 \%$ ). $\mathrm{NaPF}_{6}$ was purchased from Acros Organics (purity > $98.5 \%$ ) and $\mathrm{NaBC}_{24} \mathrm{H}_{20}$ (NaTPB) from Sigma Aldrich (purity > 99.5\%). $\mathrm{NaCl}, \mathrm{NaBr}$ and NaI were baked in an oven at $300{ }^{\circ} \mathrm{C}$ for 2 hours, while $\mathrm{NaNO}_{3}$ was baked at $250{ }^{\circ} \mathrm{C} . \mathrm{NaClO}_{4} \cdot \mathrm{H}_{2} \mathrm{O}, \mathrm{NaSCN}$, $\mathrm{NaPF}_{6}$ and NaTPB were not thermally treated prior to solution preparation (they are not very stable upon heating). Salt solutions were prepared using ultrapure water (specific resistance of 18.2 $\mathrm{M} \Omega \mathrm{cm}$ ) produced by an Arium 611UV (Sartorius) reverse osmosis unit. 


\subsection{Pressure-area isotherms of Langmuir monolayers}

Isotherm measurements were carried out with a KSV Minitrough (KSV Instruments, Finland) equipped using a Wilhelmy plate made of platinum for the determination of the surface pressure with accuracy $\pm 0.01 \mathrm{mN} \mathrm{m}^{-1}$. The trough surface area was $273 \mathrm{~cm}^{2}$ and the subphase volume was $190 \mathrm{~mL}$. All experiments were performed at $(12.0 \pm 0.1){ }^{\circ} \mathrm{C}$, with the exception of a few experiments on pure water (reported in Figure 1), which were made at different temperatures to compare with available literature data and to decide on which low temperature to use. The temperature of the subphase was maintained constant with a Julabo recirculating thermostat. DPPC monolayers were obtained by spreading $30 \mu \mathrm{L}$ or less of a 1 $\mathrm{mM}$ chloroform solution of DPPC. After $15 \mathrm{~min}$ of evaporation time for the spreading solvent, the surface pressure - area isotherms were registered while compressing symmetrically the monolayers at a constant speed of $10 \mathrm{~mm} / \mathrm{min}$. For all concentrations of every salt used, DPPC isotherms were measured at least four to five times, or as many times as necessary to ensure reproducibility and obtain an accurate average isotherm.

\subsection{Brewster Angle Microscopy (BAM)}

A Brewster angle microscope (BAM 300, Optrel, Germany) was used to study the morphology of the lipid monolayers. The instrument uses a $10 \mathrm{~mW}$ He-Ne laser, which emits p-polarized monochromatic light at $632.8 \mathrm{~nm}$. The BAM 300 is fitted with an EHD $^{\circledR}$ kamPro02 digital monochromatic camera, with a CCD sensor ( $1 / 2$ " SuperHAD). The lens (Mitutoyo) has a focusing area of 400x300 $\mu \mathrm{m}$ and a lateral resolution of $2 \mu \mathrm{m}$. Because the Brewster angle changes with the refractive index of the subphase, which is influenced significantly by electrolytes, special care was taken to identify the correct Brewster angle especially for salt solutions with high concentration. The Brewster angle was always $>53.5^{\circ}$. 


\subsection{Grazing Incidence X-ray Diffraction (GIXD)}

Grazing incidence X-ray diffraction was performed using the liquid-surface diffractometer at the undulator beamline BW1 at HASYLAB, DESY, Hamburg (Germany). Details of the setup for measurements on Langmuir monolayers have been given before. ${ }^{40}$ The Langmuir trough ( $\mathrm{R} \& \mathrm{~K}$, Potsdam, Germany) was placed in a hermetically-closed metal box, which was sealed prior to the start of each measurement. The trough was thermostated at $12{ }^{\circ} \mathrm{C}$ using an external water recirculator. To reduce water evaporation and the scattering of x-rays from air, the oxygen levels in the systems were monitored and kept low by exchanging the air in the metal box with moistened gaseous helium. A hydrophilic plate of borosilicate material was placed into the trough under the monolayer to avoid capillary waves produced from mechanical vibrations of the set-up. ${ }^{41}$ Because X-rays can cause significant damage to the monolayer, the trough was moved between scans, so that the beam was hitting a different sample area every time. ${ }^{42,43}$

A monochromatic X-ray beam $(\lambda=1.3038 \AA)$, produced by the synchrotron beam after Laue reflection from a beryllium (2 00 ) monocrystal, entered the monolayer surface at an angle of incidence $\alpha_{i}=0.85 \alpha_{c}$, where $\alpha_{c} \approx 0.13^{\circ}$ is the critical angle for total reflection. A linear position-sensitive detector (PSD - OEM-100-M, Braun, Garching, Germany) was used to monitor the diffracted intensity as a function of the vertical scattering angle $\alpha_{\mathrm{f}}$ with vertical acceptance $0<\mathrm{Q}_{\mathrm{z}}<0.8 \AA^{-1}$. For in-plane diffraction measurements, a vertically oriented Soller collimator giving a lateral resolution of $\Delta \mathrm{Q}_{\mathrm{xy}}=0.008 \AA^{-1}$ was placed in front of the detector. This configuration allowed Bragg peak and Bragg rod measurements to be made simultaneously. According to the geometry of diffraction, the scattering vector $\mathbf{Q}$ can be written in terms of an in-plane component $\mathrm{Q}_{\mathrm{xy}}$ and an out-of plane component $\mathrm{Q}_{\mathrm{z}}:^{44-49}$

$$
\mathrm{Q}_{\mathrm{xy}}=\frac{2 \pi}{\lambda} \sqrt{\cos ^{2} \alpha_{\mathrm{i}}+\cos ^{2} \alpha_{\mathrm{f}}-2 \cos \alpha_{\mathrm{i}} \cos \alpha_{\mathrm{f}} \cos 2 \theta}
$$


and

$$
\mathrm{Q}_{\mathrm{z}}=\frac{2 \pi}{\lambda}\left(\sin \alpha_{\mathrm{i}}+\sin \alpha_{\mathrm{f}}\right) \approx \frac{2 \pi}{\lambda} \sin \alpha_{\mathrm{f}} \quad \text { when } \alpha_{\mathrm{i}}<<\alpha_{\mathrm{f}}
$$

Where $\alpha_{\mathrm{i}}, \alpha_{\mathrm{f}}$ and $\theta$ are the incident, vertical and horizontal angles respectively. The in-plane component of the scattering vector provides information about the lattice spacings:

$$
\mathrm{d}_{\mathrm{hk}}=\frac{2 \pi}{\mathrm{Q}_{\mathrm{xy}}}
$$

From these one can deduce the lattice type and lattice parameters (lengths a and $\mathrm{b}$ and angle $\gamma)$, according to

$$
\mathrm{d}_{\mathrm{hk}}=\left\{\left(\frac{\mathrm{h}}{\mathrm{a}}\right)^{2}+\left(\frac{\mathrm{k}}{\mathrm{b}}\right)^{2}-2 \frac{\mathrm{hk} \cos \gamma}{\mathrm{ab}}\right\}^{-1 / 2} \sin \gamma
$$

The area per lipid molecule at the "horizontal" plane $\mathrm{x}-\mathrm{y}$ is given by

$$
A_{x y}=a b \sin \gamma
$$

The out-of plane component of the scattering vector can provide information about the polar tilt angle, $\mathrm{t}$, and the chain tilt direction $\Psi$ (azimuth $\Psi) .^{46,47}$

$$
\mathrm{Q}_{\mathrm{z}}^{\mathrm{hk}}=\mathrm{Q}_{\mathrm{xy}}^{\mathrm{hk}} \cos \Psi_{\mathrm{hk}} \operatorname{tant}
$$

For a distorted hexagonal lattice with NN-tilted chains Eq. (6) becomes: $:^{48,49}$ 


$$
\tan t=\frac{Q_{z}^{d}}{\sqrt{\left(Q_{x y}^{d}\right)^{2}-\left(Q_{x y}^{n} / 2\right)^{2}}}
$$

Where $\mathrm{d}$ and $\mathrm{n}$ denote the degenerate (11) and non-degenerate (02) peaks observed in this case. For the NN-tilted phase the "lattice distortion" with respect to a perfect hexagonal lattice is given by: ${ }^{49}$

$$
\varepsilon=\frac{8}{3} \frac{\left(Q_{x y}^{d}-Q_{x y}^{n}\right)}{\left(Q_{x y}^{d}+Q_{x y}^{n}\right)}
$$

The widths of the diffraction peaks determine correlation lengths for the monolayer through a Scherrer formula:

$$
\mathrm{L}=0.88 \times \frac{2 \pi}{\mathrm{FWHM}}
$$

Here FWHM is the width of the peak at half maximum corrected for effects of instrumental resolution. Eq. (9) is valid both in the $\mathrm{x}-\mathrm{y}$ plane and in the $\mathrm{z}$-direction. In the $\mathrm{z}$-direction, $\mathrm{L}_{\mathrm{z}}$ provides evidence about the degree of internal order of a chain (its magnitude reflects the percentage of trans bonds in the hydrocarbon chains). In the $x-y$ plane the correlation lengths determine the size of the monocrystalline domains. Knowing $\mathrm{L}_{\mathrm{xy}}$ from the (11) and (02) peaks, one can obtain a rough estimate of the number of lipid molecules in a monocrystal, by treating the average crystalline domain as an ellipse:

$$
\mathrm{N}_{1}^{\mathrm{cr}}=\frac{\pi \mathrm{L}_{\mathrm{xy}}^{(11)} \mathrm{L}_{\mathrm{xy}}^{(02)}}{8 \mathrm{~A}_{\mathrm{xy}}}
$$


Where the correlation lengths are assumed to be equal to the axes of the ellipsoidal domain and the molecular cross-section is equal to $2 \mathrm{~A}_{\mathrm{xy}}$ for double-chain phospholipids. GIXD measurements were taken at $10,20,30$ and $40 \mathrm{mN} \mathrm{m}^{-1}$ for pure water subphase and for most electrolytes, with the exception of NaTPB. For the higher concentrations of this salt that were used we could not detect a signal at low pressures, so we extended the measurement range to $60 \mathrm{mN} \mathrm{m}^{-1}$

\subsection{Infrared Reflection-Absorption Spectroscopy (IRRAS)}

IRRAS spectra were recorded using the IFS 66 FT-IR spectrometer (Bruker, Germany) equipped with a liquid nitrogen-cooled MCT detector. The IR beam was conducted out of the spectrometer and focused onto the water surface of the Langmuir trough. A detailed description of the instrumental setup has been given elsewhere. ${ }^{50}$ The angle of incidence of the IR beam, polarized by a KRS-5 wire grid polarizer in the plane of incidence (p) and perpendicular to this plane (s), was $40^{\circ}$ or $60^{\circ}$ with respect to the surface normal. Measurements were made by switching between two troughs at regular intervals using a trough shuttle system controlled by the acquisition computer. One trough contains the monolayer system under investigation (sample), whereas the other (reference) is filled with pure subphase. The two troughs are connected through small holes so that the subphase level

is identical in both. To maintain a constant water vapor content the set-up was placed in a hermetically sealed container. The beam reflected at an angle equal to the angle of incidence is guided to a MCT detector, kept under very low temperature by cooling with liquid nitrogen. The spectra from the reference trough, $\mathrm{R}_{0}$, were subtracted from the sample spectra, $\mathrm{R}$, in order to eliminate the water vapor signal, and the IRRAS spectrum is reported as $-\log \left(R / R_{0}\right)$. Spectra were recorded with a spectral resolution of $8 \mathrm{~cm}^{-1}$ and collected using 200 scans for spolarized light and 400 scans for p-polarized light. 


\section{3. $\underline{\text { Results }}$}

\subsection{Anion effects are significant and follow the lyotropic series}

The anticipated anion effect is observed in Figure 2a, where we show pressure-area isotherms of DPPC monolayers at $12{ }^{\circ} \mathrm{C}$ on solutions of sodium thiocyanate ( $\left.\mathrm{NaSCN}\right) . \mathrm{SCN}^{-}$is known to have a strong effect on DPPC monolayers at higher temperatures. ${ }^{1-5}$ The partition coefficient of $\mathrm{SCN}^{-}$between the monolayer and bulk water at $22{ }^{\circ} \mathrm{C}$ is among the highest calculated, implying in fact a specific interaction of the ion with the phospholipids. ${ }^{4}$ Two separate populations of $\mathrm{SCN}^{-}$ions have been detected under DPPC monolayers using vibrational sum frequency generation spectroscopy. ${ }^{5}$

(a)

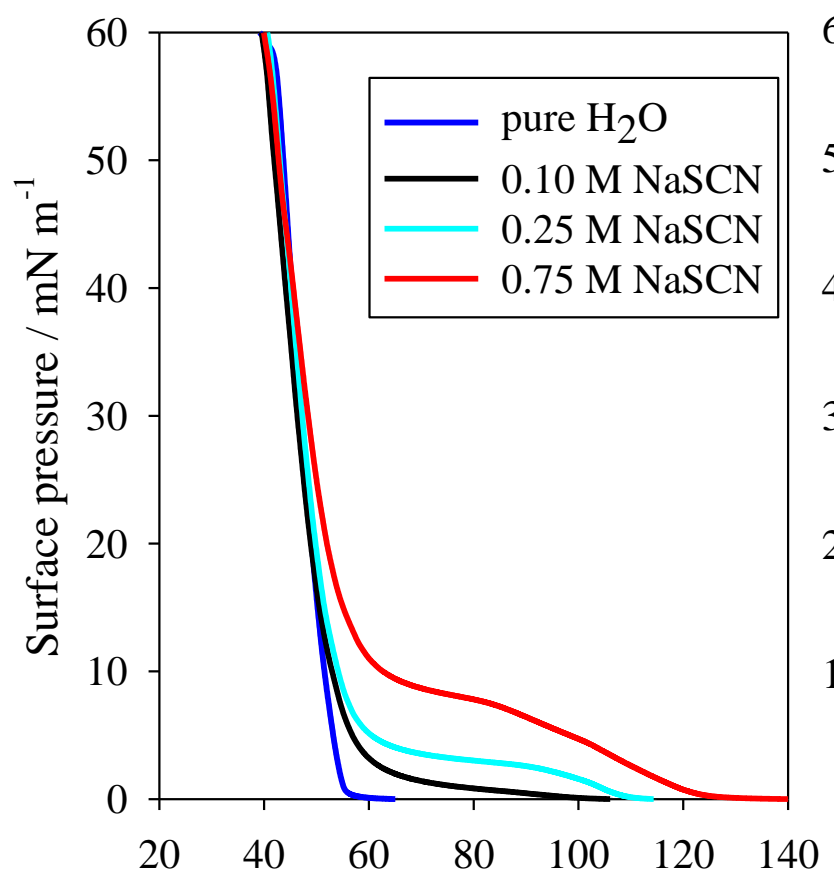

(b)

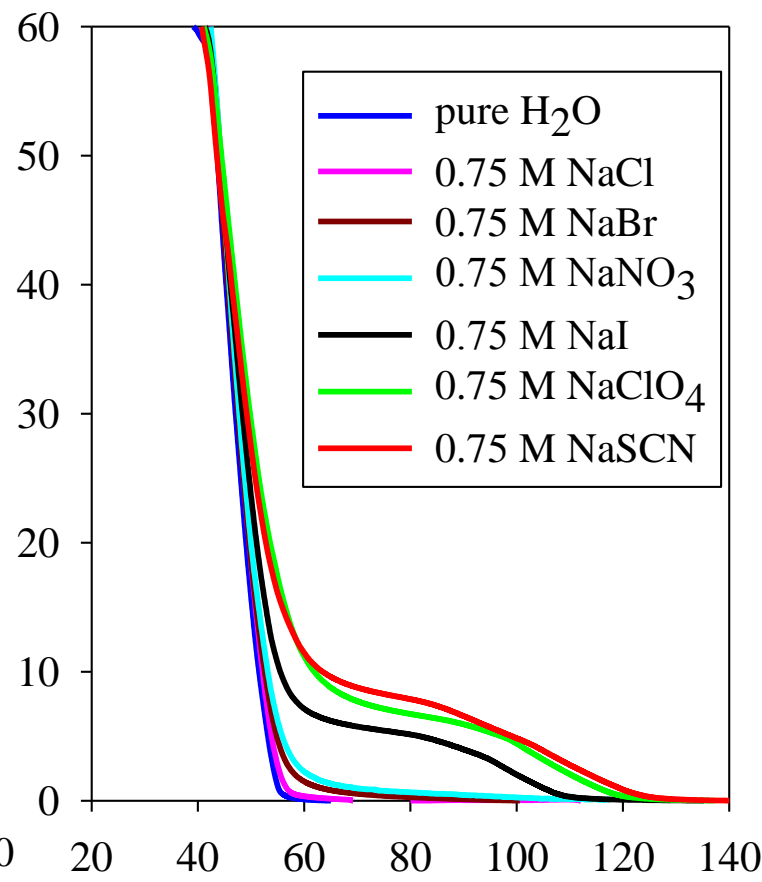

Area per DPPC molecule / $\mathrm{A}^{2}$

Figure 2: (a) Pressure - area isotherms of DPPC monolayers at $12{ }^{\circ} \mathrm{C}$ on (a) NaSCN solutions of various concentrations, and (b) $0.75 \mathrm{M}$ solutions of different sodium salts. 
In Figure 2a we see that the presence of $\mathrm{NaSCN}$ in the subphase leads to increased disorder, and an appearance of a plateau that looks like a classic LE-LC equilibrium. As the salt concentration increases, the pressure of the plateau increases, as does also the range of molecular areas over which the monolayer LE-like disorder becomes obvious. This is an anion-specific effect, as corroborated by the results in Figure 2b, where we see the isotherms obtained for a number of sodium salts in the subphase at a concentration of $0.75 \mathrm{M}$. The results in Figure $2 \mathrm{~b}$ demonstrate that more chaotropic salts produce a stronger effect at the same concentration. The very weak effects of marginally chaotropic anions, such as $\mathrm{Cl}^{-} \mathrm{or} \mathrm{Br}^{-}$, raise the question of "concentration onset". What concentration of a particular salt is needed for a visible disordering effect? Since there is not a clear or unique criterion to resolve this issue, we have opted to monitor the isotherm pressure at a molecular area, at which a clear LE phase is observed at high salt concentrations. This happens at roughly $100 \AA^{2}$ per molecule for most salts, small changes being allowed because the range of the LE phase is slightly shifting, depending on the salt. In Figure 3 we show the pressure at this lipid area per molecule as a function of salt concentration for most of the salts used in this study.

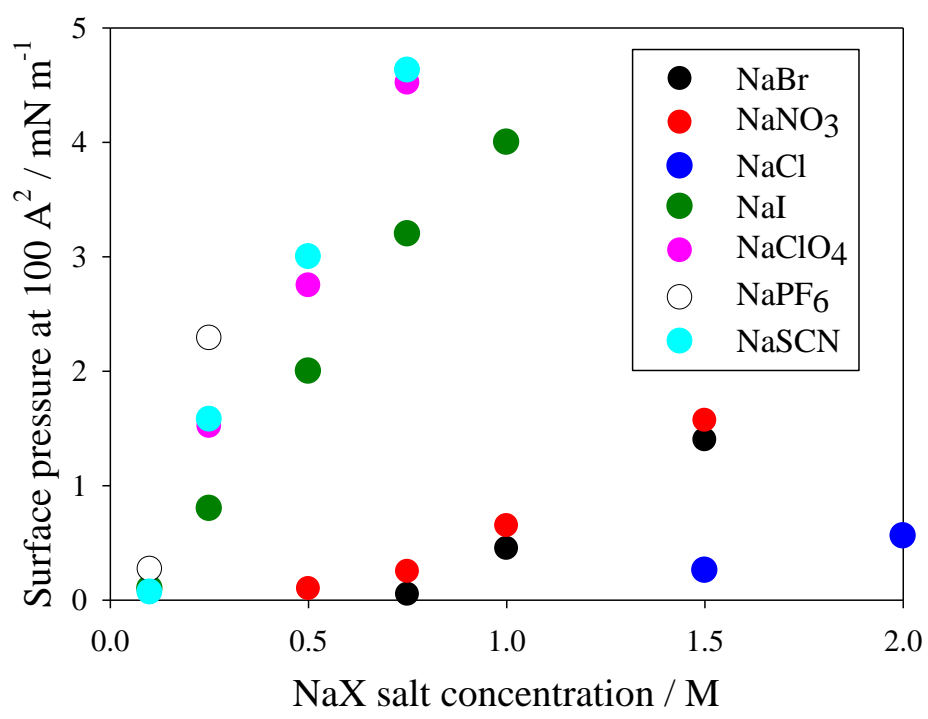

Figure 3: Monolayer surface pressure at $100 \AA^{2}$ per DPPC molecule as function of salt type and concentration. 
The lyotropic series clearly emerges from this plot, since the concentration onset for visible salt effects is in the order $\mathrm{NaPF}_{6}<\mathrm{NaSCN} \approx \mathrm{NaClO}_{4}<\mathrm{NaI}<\mathrm{NaNO}_{3}<\mathrm{NaBr}<\mathrm{NaCl}$. It is tempting to define an "onset concentration" from a linear extrapolation of the data for each salt, but there are good reasons to avoid this, namely (a) there is no theoretical justification to pass straight lines through these data, (b) for some salts there are not enough points to decide the issue, and (c) for some salts we get the impression that the behavior close to the "onset" is nonlinear. A clear nonlinear behavior at much lower concentrations is observed for the "hydrophobic" NaTPB. This will be discussed in a forthcoming publication.

\subsection{Anions disrupt DPPC monolayers at all length scales}

How and to what extent do anions affect the structure of DPPC monolayers at low temperatures? A complete answer is obtained by examining evidence from several techniques providing information at different length scales. BAM images obtained at various surface pressures are shown in Figure 4. They show that even at zero pressure the DPPC monolayers over water at $12{ }^{\circ} \mathrm{C}$ are ordered to a considerable extent.

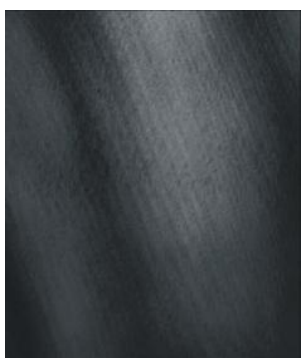

(a)

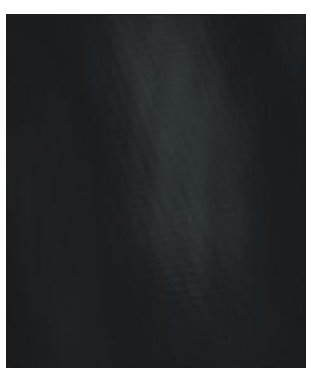

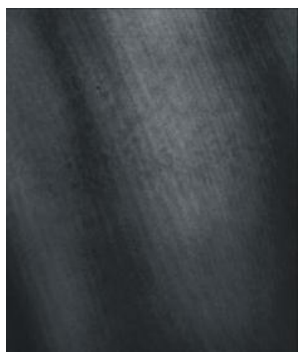

(b)

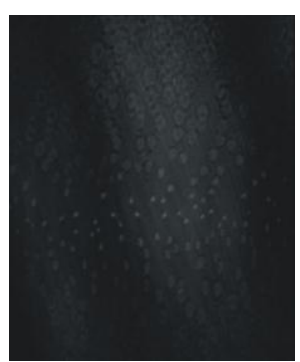

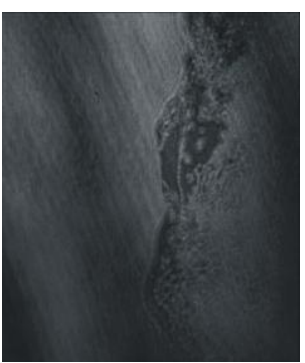

(c)

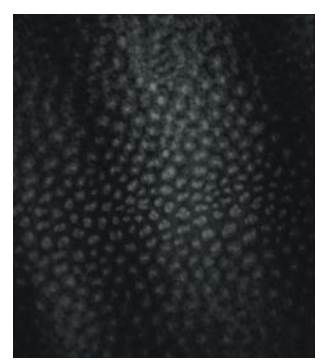

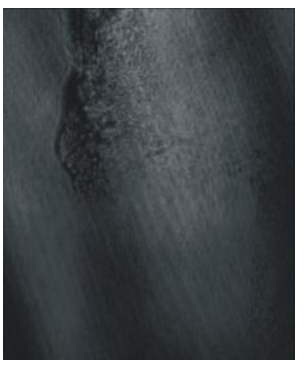

(d)

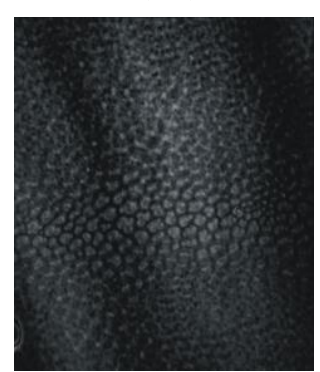

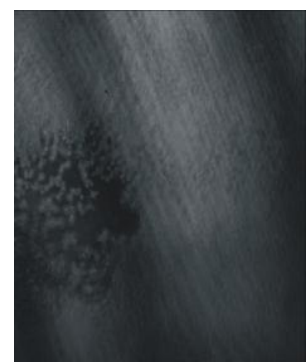

(e)

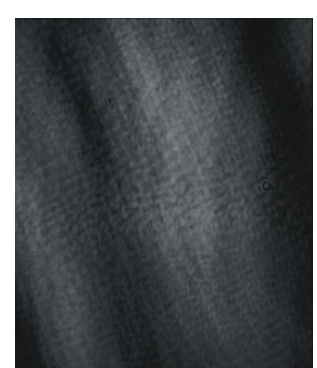


Figure 4: BAM images of DPPC monolayers at $12{ }^{\circ} \mathrm{C}$ on (top) a pure water subphase, and (bottom) a $0.5 \mathrm{M} \mathrm{NaSCN}$ solution, at the following areas per molecule (from left to right): (a)

$$
120 \AA^{2}, \text { (b) } 90 \AA^{2} \text {, (c) } 80 \AA^{2} \text {, (d) } 70 \AA^{2} \text {, (e) } 60 \AA^{2} \text {. }
$$

At relatively high molecular areas a condensed phase presumably coexists with a gaseous phase. The attractive, cohesive forces between lipids apparently are strong enough (and entropic effects are considerably weakened) to allow formation of extensive ordered domains in equilibrium with gaseous-state regions, essentially depleted of molecules. The mesoscopic structure of the monolayer on pure water changes very little upon increasing compression, the only effect being the disappearance of gaseous voids, which occurs below $60 \AA^{2}$ per molecule. When $0.5 \mathrm{M} \mathrm{NaSCN}$ is present in the subphase the situation is quite different. At large areas per molecule no ordered domains are visible (hence the darker uniform image seen in Figure 4, bottom, left). The monolayer is fully disordered, being in a pure LE phase or a coexistence of LE and gaseous states. At $90 \AA^{2}$ per molecule the first domains of the ordered LC phase appear, which increase in number and size as the monolayer is compressed and eventually coalesce into a LC phase, similar to that observed on pure water. In fact, the sequence of images obtained on $0.5 \mathrm{M} \mathrm{NaSCN}$ is quite similar to the BAM observations at higher temperatures. ${ }^{1}$ The individual domains have the branched geometry with two, three (triskelion) or four branches normally obtained for DPPC, ${ }^{51-54}$ and known to partly depend on compression speed and time available for monolayer relaxation. ${ }^{55}$ The sequence of BAM images obtained at other $\mathrm{NaSCN}$ concentrations $(0.1 \mathrm{M}$, and $0.25 \mathrm{M})$ are in complete agreement with the results of Figure 4. The conclusion from the BAM investigation is that on water at $12{ }^{\circ} \mathrm{C}$ DPPC forms extensive LC phase domains in equilibrium with a gaseous phase. These domains appear to "dissolve" in the presence of salts, a LE phase is formed, and the 
monolayer subsequently evolves in a way exactly analogous to that observed on water at higher temperatures. ${ }^{1}$

Infrared Reflection-Absorption Spectroscopy (IRRAS) was used to provide information about the influence of electrolytes on DPPC monolayers at the molecular scale. From previous FTIR studies we know that changes in the wavenumbers and intensities of specific bands provide valuable information on chain conformation $\left(v_{a s} \mathrm{CH}_{2}, v_{s} \mathrm{CH}_{2}\right)$, H-bonding, hydration and ion binding to the headgroup of the lipid $\left(v \mathrm{CO}, v_{a s} \mathrm{PO}_{2}{ }^{-}\right) .{ }^{56-58}$ Particularly interesting are (a) the $\mathrm{C}-\mathrm{H}$ stretching bands of the saturated hydrocarbon chains between 3000 and $2800 \mathrm{~cm}^{-1}$, and (b) the region between 1740 and $1700 \mathrm{~cm}^{-1}$, which gives information about the vibrations of the carbonyl groups of the DPPC molecule. The C-H region of the IRRAS pattern is shown in Figure 5a for DPPC monolayers on water or NaSCN solutions at $12{ }^{\circ} \mathrm{C}$ and $10 \mathrm{mN} \mathrm{m}^{-1}$. The two prominent bands at ca. $2851 \mathrm{~cm}^{-1}$ and ca. $2920 \mathrm{~cm}^{-1}$ are due to the symmetric and antisymmetric $\mathrm{CH}_{2}$ stretching vibrations of the alkyl chains of the phospholipids, respectively. It is known that during the LE-LC phase transition in DPPC monolayers the symmetric $\mathrm{CH}_{2}$ stretching frequency decreases from 2855 to $2851 \mathrm{~cm}^{-1}$ and the antisymmetric $\mathrm{CH}_{2}$ decreases from 2924 to $2919 \mathrm{~cm}^{-1}$, indicating an increase of trans over gauche conformations and a higher degree of order in the monolayer. ${ }^{59,60}$ 

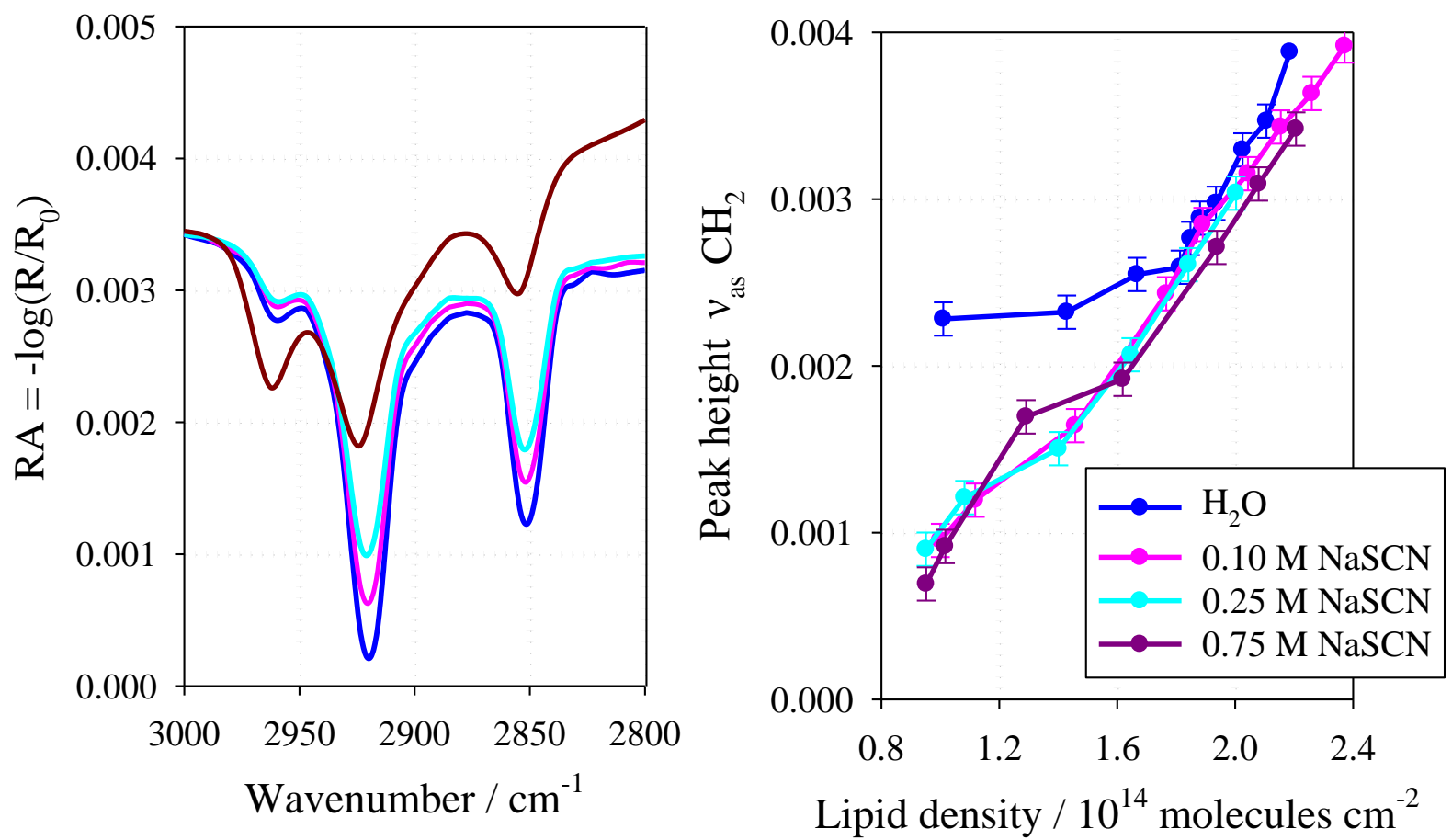

Figure 5: (a) The C-H region of the IRRAS spectrum of DPPC monolayers on pure water and 0.1 M, 0.25 M and 0.75 M NaSCN solutions at $12{ }^{\circ} \mathrm{C}$ and $5 \mathrm{mN} \mathrm{m}^{-1}$. (b) Plots of the $v_{\mathrm{as}} \mathrm{CH}_{2}$ peak height vs. lipid density for DPPC monolayers on the same solutions.

The intensities of the bands decrease as the NaSCN concentration increases, indicating a progressively lower order in the monolayer. The behavior of these two bands is quite similar, so we focus on the antisymmetric (as) band. The height of the peak is plotted vs. the surface density of the lipid molecules (which is the inverse of the area per molecule) for DPPC monolayers on these NaSCN solutions. Linearity of this plot implies that the intensity increases primarily because of the increased surface density of contributing groups, while the average chain conformation is roughly constant. Only minor deviations from linearity are observed in the region of the LE-LC transition on the NaSCN solutions, even though the chains undergo an ordering transition and there is a continuous change of the tilt angle with pressure in the condensed phase (see below). Perfect linearity was observed before in such plots for DPPC Langmuir-Blodgett films deposited on Ge surfaces, ${ }^{61}$ although a clear break 
was observed for dipalmitoyl phosphatidylglycerol monolayers on water. ${ }^{62}$ In Figure $5 b$ we do see an obvious break for the data over pure water. The peak heights are larger than those on NaSCN solutions, indicating a higher ordering of the monolayers on pure water. At low lipid densities the peak heights are almost insensitive to the lipid density in the pure water case, showing that the "true" lipid density changes little, because as we compress the monolayer we mainly remove gaseous voids, but do not change the condensed phase conformations.

In Figure 6 we see that the wavenumber of the as band on pure water is low and quite insensitive to surface pressure. This is a strong indication that the monolayer is largely ordered even at very low pressures, corroborating the BAM evidence, since wavenumber values around $2925 \mathrm{~cm}^{-1}$ indicate disorder in the chain region (significant presence of gauche conformers), while values below $2920 \mathrm{~cm}^{-1}$ are typical for all-trans conformations.

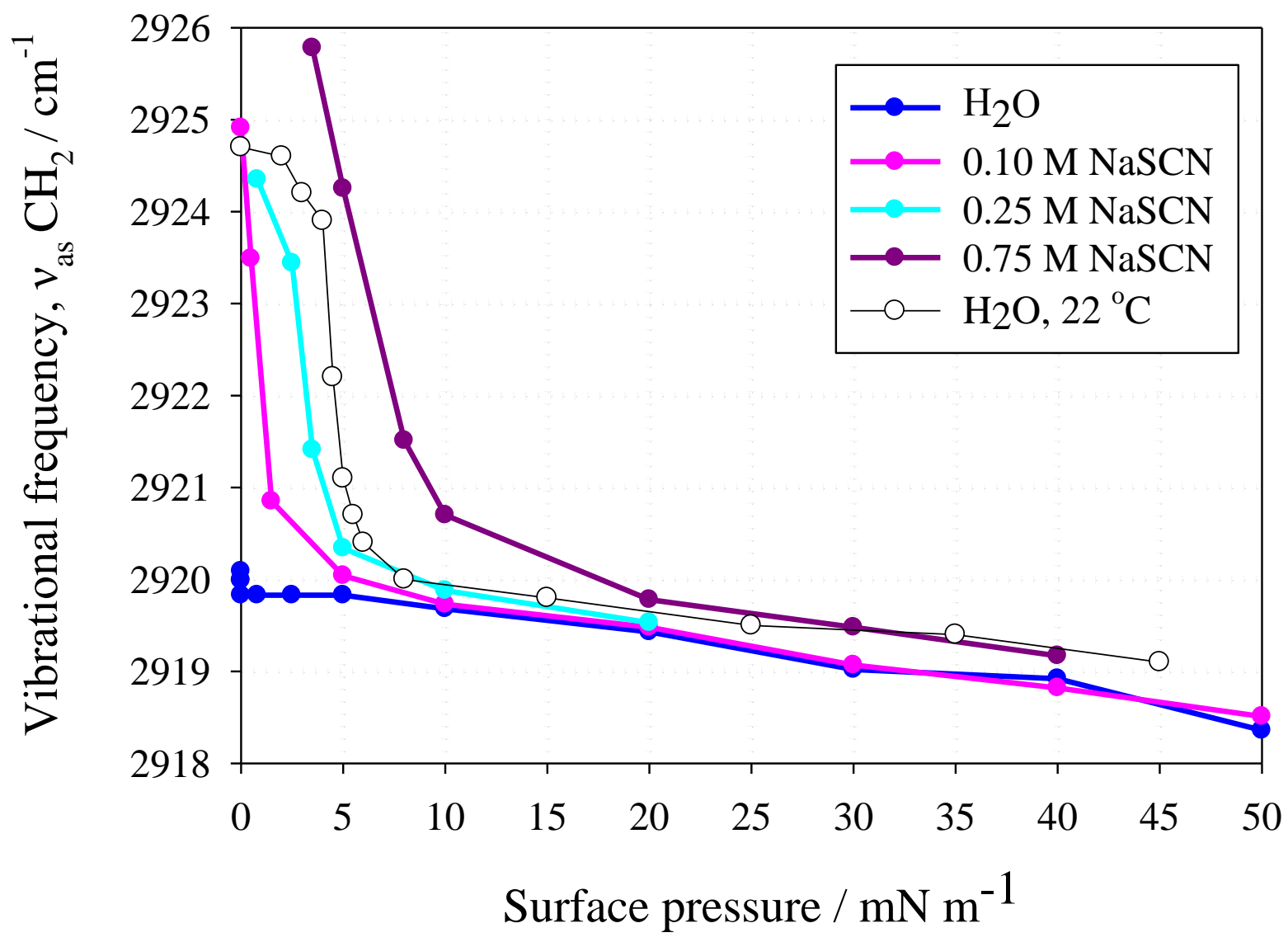


Figure 6: Wavenumbers of as $\mathrm{CH}_{2}$ stretching vibrations of a DPPC monolayer on pure water and $\mathrm{NaSCN}$ solutions of various concentrations vs. surface pressure. The lines are drawn to guide the eye. s-polarized light at an angle of $40^{\circ}$ normal to the surface was used.

At low surface pressures we observe that the wavenumber increases considerably in the presence of NaSCN in the subphase. This behavior is much closer to the behavior on pure water at higher temperatures, indicating the "melting" of condensed phase domains at low pressures and the passage from a LE to a LC phase with increasing surface pressure. Similar results have been obtained for DPPC monolayers on solutions of the other chaotropic anions. In Figure 7 we see the carbonyl group region of the IRRAS spectrum for DPPC monolayers on $0.25 \mathrm{M} \mathrm{NaClO}_{4}$ solutions at $12{ }^{\circ} \mathrm{C}$ at various surface pressures. The corresponding spectra on pure water are provided as Figure S1 in the Electronic Supporting Information section. The carbonyl spectra of phospholipids are usually thought to consist of several peaks that reflect molecules with varying degrees of hydration. ${ }^{63-65}$ Peaks at roughly $1740,1726,1710$ and 1685 $\mathrm{cm}^{-1}$ have been identified for lipid molecules with progressively larger hydration (zero, one, two and three hydrogen bonds with water molecules). As can be seen in Figure 7 and also Figure S1, both bands at 1740 and $1726 \mathrm{~cm}^{-1}$ are present, the second being more pronounced. As the pressure increases and the monolayer goes gradually to the ordered LC phase, the peak at $1740 \mathrm{~cm}^{-1}$, which corresponds to the non-hydrogen-bonded lipids, becomes more dominant as expected, since the contact of the carbonyls with water becomes progressively more difficult. A shoulder at about $1710 \mathrm{~cm}^{-1}$ (indicating the presence of more hydrated lipid states) is visible in all spectra and appears to be enhanced at low pressures and in the presence of electrolyte. Overall however it is found that spectra in the carbonyl region are not strongly affected by the presence of chaotropic anions. A similar conclusion can be drawn by examining the region of the phosphate group vibrations $\left(v_{\mathrm{as}} \mathrm{PO}_{2}\right.$ vibration in the range 1220- 
$\left.1260 \mathrm{~cm}^{-1}\right)$. We conclude therefore that lipid hydration is not greatly perturbed, even in the presence of large concentrations of sodium salts of chaotropic anions.

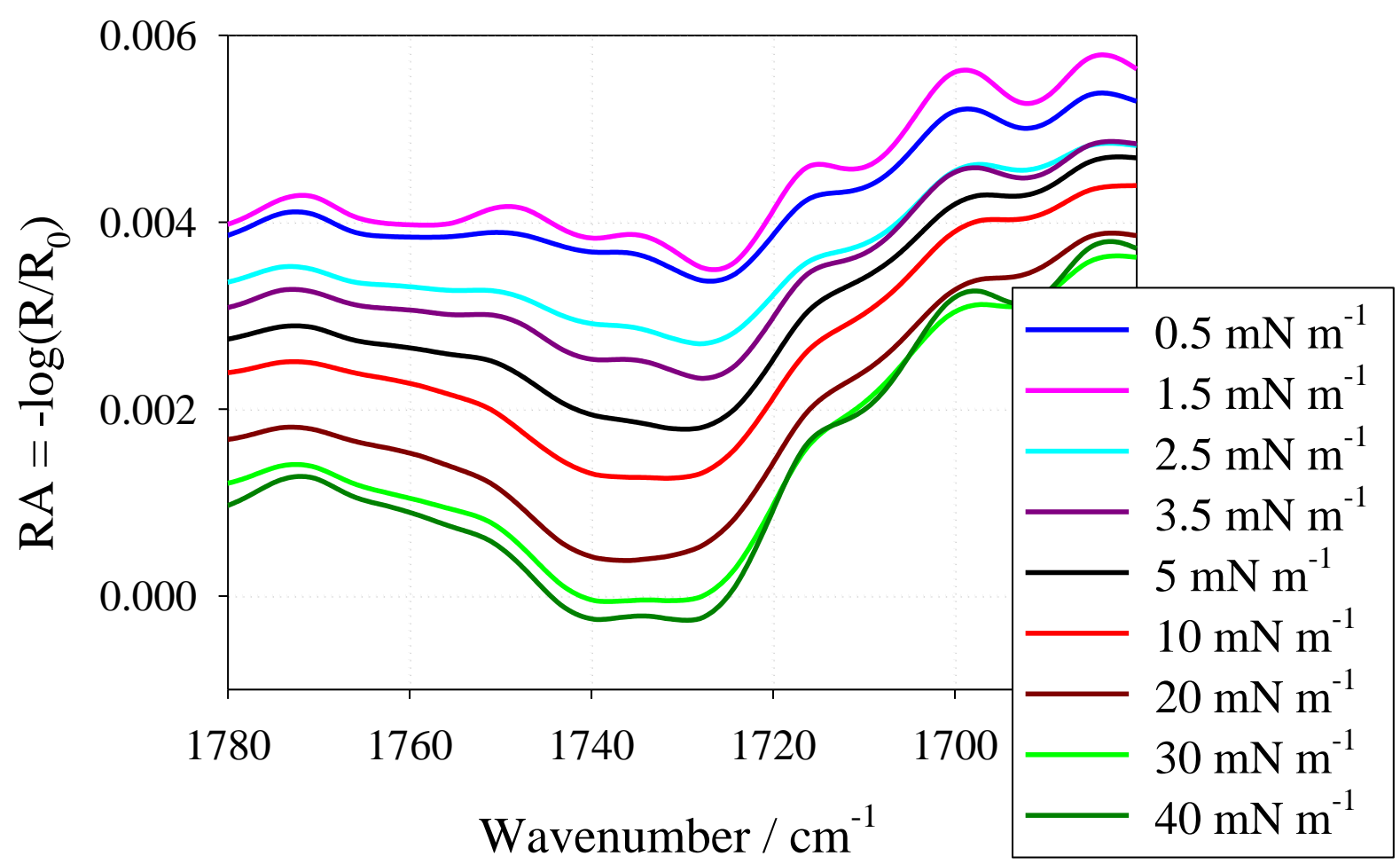

Figure 7: IRRAS spectrum of a DPPC monolayer in the region of the $\mathrm{C}-\mathrm{O}$ stretching vibrations on a $0.25 \mathrm{M} \mathrm{NaClO}_{4}$ solution at various surface pressures. s-polarized light at an angle of $40^{\circ}$ normal to the surface was used.

The final aspect of electrolyte effects on DPPC monolayers at $12{ }^{\circ} \mathrm{C}$ is provided by examining the structure of the LC phase at higher pressures using the GIXD method. Table 1 contains the extracted geometric parameters of the $\mathrm{LC}$ phase on pure water and $\mathrm{NaClO}_{4}$ solutions of various concentrations. Table 2 contains comparative results for DPPC LC phases on $0.25 \mathrm{M}$ solutions of $\mathrm{NaNO}_{3}, \mathrm{NaSCN}$ and $\mathrm{NaPF}_{6}$. Several conclusions can be drawn from these results. In the first place the electrolytes affect the lattice parameters of the LC phase in a systematic way. In most cases the lattice itself can be identified as the NN-tilted distorted hexagonal phase that is usually observed for DPPC monolayers. ${ }^{1,2,42,66-68}$ The lattice 
dimensions increase slightly with increasing electrolyte concentration (see Table 1 for the $\mathrm{NaClO}_{4}$ effect), although for the very chaotropic $\mathrm{NaPF}_{6}$ a partial reversal of the trend is found. The lattice distortion is plotted in Figure S2 in the Electronic Supporting Information section as a function of $\sin ^{2}(t), t$ being the molecular tilt angle. Such plots are expected to be linear, a fact explained by Landau theory. ${ }^{49}$ The linearity of these plots is indeed excellent and the slopes increase with increasing salt concentration, as we can see for $\mathrm{NaNO}_{3}$ and $\mathrm{NaClO}_{4}$, although a break in this pattern is once more seen for $\mathrm{NaPF}_{6}$. Similarly the tilt angle increases in the presence of electrolytes, which may be ascribed to the expansion of the monolayer at fixed surface pressure. A plot of the inverse cosine of the tilt angle, $1 / \cos (t)$ as a function of surface pressure is roughly linear with a negative slope, ${ }^{69-71}$ and the position at which $\cos (t)$ becomes unity indicates the surface pressure at which the lipids would adopt an untilted conformation. In Figure 8 we see that for most systems such pressures are typically higher than $70 \mathrm{mN} / \mathrm{m}$, at which pressures the monolayers are past the collapse point. Figure 8 thus indicates that the tilted phase of DPPC persists at $12{ }^{\circ} \mathrm{C}$ even at high concentrations of most electrolytes. An interesting exception to this rule is $\mathrm{NaPF}_{6}$, a salt with a very chaotropic anion, for which an untilted phase of the DPPC monolayer might appear at surface pressures of $50 \mathrm{mN} \mathrm{m}^{-1}$ or higher (unfortunately measurements at such high pressures could not be carried out!). 


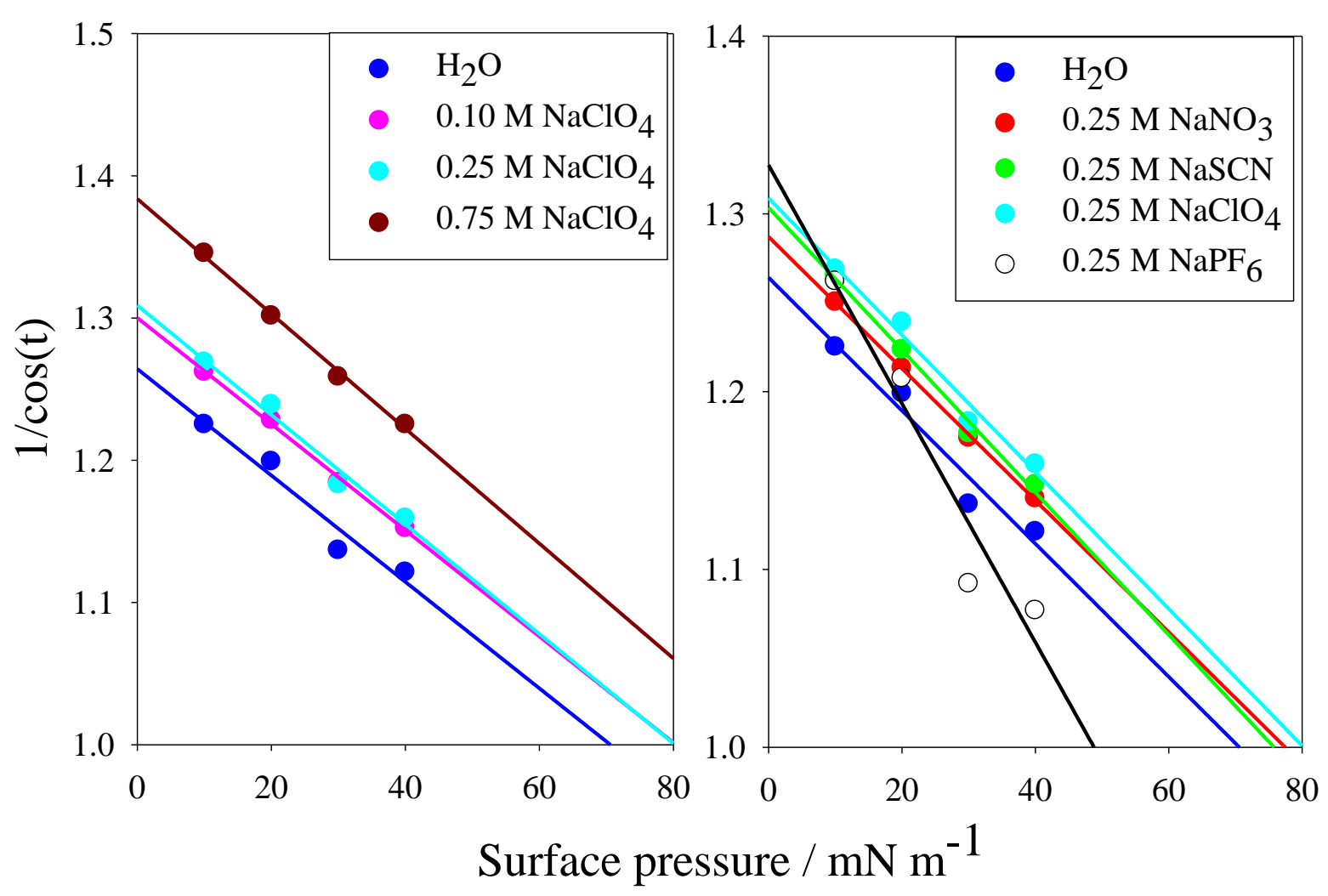

Figure 8: Plot of the inverse cosine of the tilt angle of the DPPC monolayer as a function of surface pressure (a) on $\mathrm{NaClO}_{4}$ solutions of various concentrations and (b) on $0.25 \mathrm{M}$ solutions of various electrolytes.

From the results of Figure 8 the following question emerges: Would a sufficiently high concentration of a very chaotropic salt induce the appearance of an untilted DPPC phase? Such phases have almost never been observed, because of the cross sectional disparity between the DPPC headgroup and its two aliphatic chains. Observation of an untilted DPPC phase is only possible if the area requirement of the headgroup can be changed either by dehydration or reorientation from an almost parallel to a more vertical alignment. ${ }^{72-74}$ Another way to reduce the tilt angle is the insertion of alkanes into the hydrophobic part of the monolayer. ${ }^{75}$ The alkanes are incorporated into the ordered lipid chains without changing the effective headgroup area, thus changing tail orientation and lattice structure. All cases that 
DPPC monolayers were reported to form untilted phases concerned mixed monolayers with other hydrophobic compounds.

In Figure 9 we see that such an effect is indeed feasible at very low concentrations of NaTPB, which contains the strongly chaotropic TPB anion.
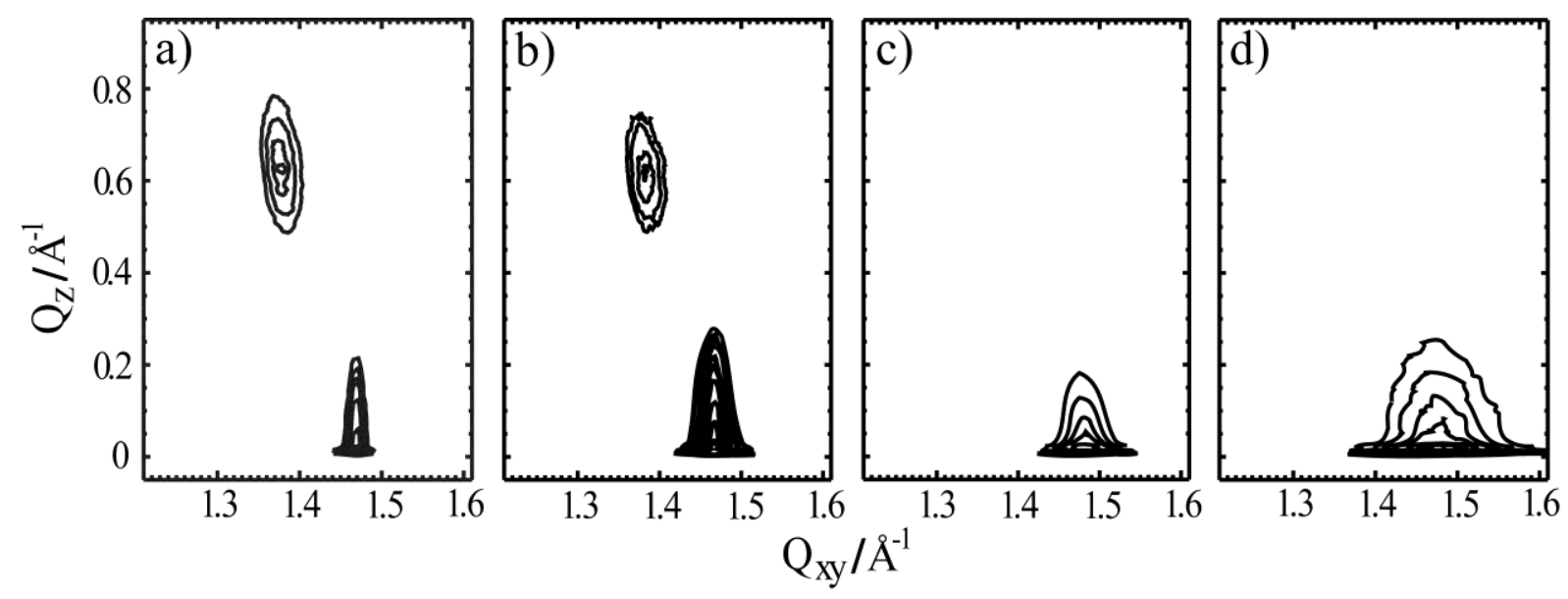

Figure 9: Contour plots of the in-plane $\mathrm{Q}_{\mathrm{xy}}$ and out-of-plane $\mathrm{Q}_{\mathrm{z}}$ scattering vector components for a DPPC monolayer on water (a) and on NaTPB solutions of various concentrations

$$
\left(5 \times 10^{-6} \mathrm{M}(\mathrm{b}), 5 \times 10^{-5} \mathrm{M}(\mathrm{c}) \text {, and } 5 \times 10^{-4} \mathrm{M}(\mathrm{d})\right) \text { at } \pi=30 \mathrm{mN} \mathrm{m}^{-1} \text { and } \mathrm{T}=12{ }^{\circ} \mathrm{C} \text {. }
$$

The (11) and (02) peaks of the usual NN-tilted distorted hexagonal phase of DPPC are found on both pure water and a $5 \times 10^{-6} \mathrm{M}$ NaTPB solutions. However at higher TPB concentrations only one peak is visible at $\mathrm{Q}_{\mathrm{z}}=0$, which means that the condensed phase exhibits a hexagonal lattice with upright (untilted) molecules. It must be noted here that, although TPB has been examined before in monolayers and has been found to form mixed monolayers with lipids, ${ }^{34-}$ ${ }^{38}$ this is the first time, as far as we know, that TPB is reported to cause a phase change in lipid monolayers. A further demonstration of the ordering in the presence of TPB is shown in Figure S3 in the Supporting Information section. There we plot the area per chain in the LC phase $\left(A_{x y}\right.$ of Eq. (5)) as a function of surface pressure. The slope of this logarithmic plot equals minus the compressibility of the LC crystalline phase. It can be seen that, with respect 
to the value on water, the compressibility increases a little in the presence of most electrolytes, but it decreases dramatically in the case of the TPB anions, since the untilted phase that is formed is very incompressible.

A final observation regarding salt effects on the condensed phase crystals is based on the peak widths (correlation lengths), which provide a measure of the crystallite size via Eq. (10). In Figure 10 we plot the number of lipids in a single crystalline domain of the LC phase for the various systems studied in this work.

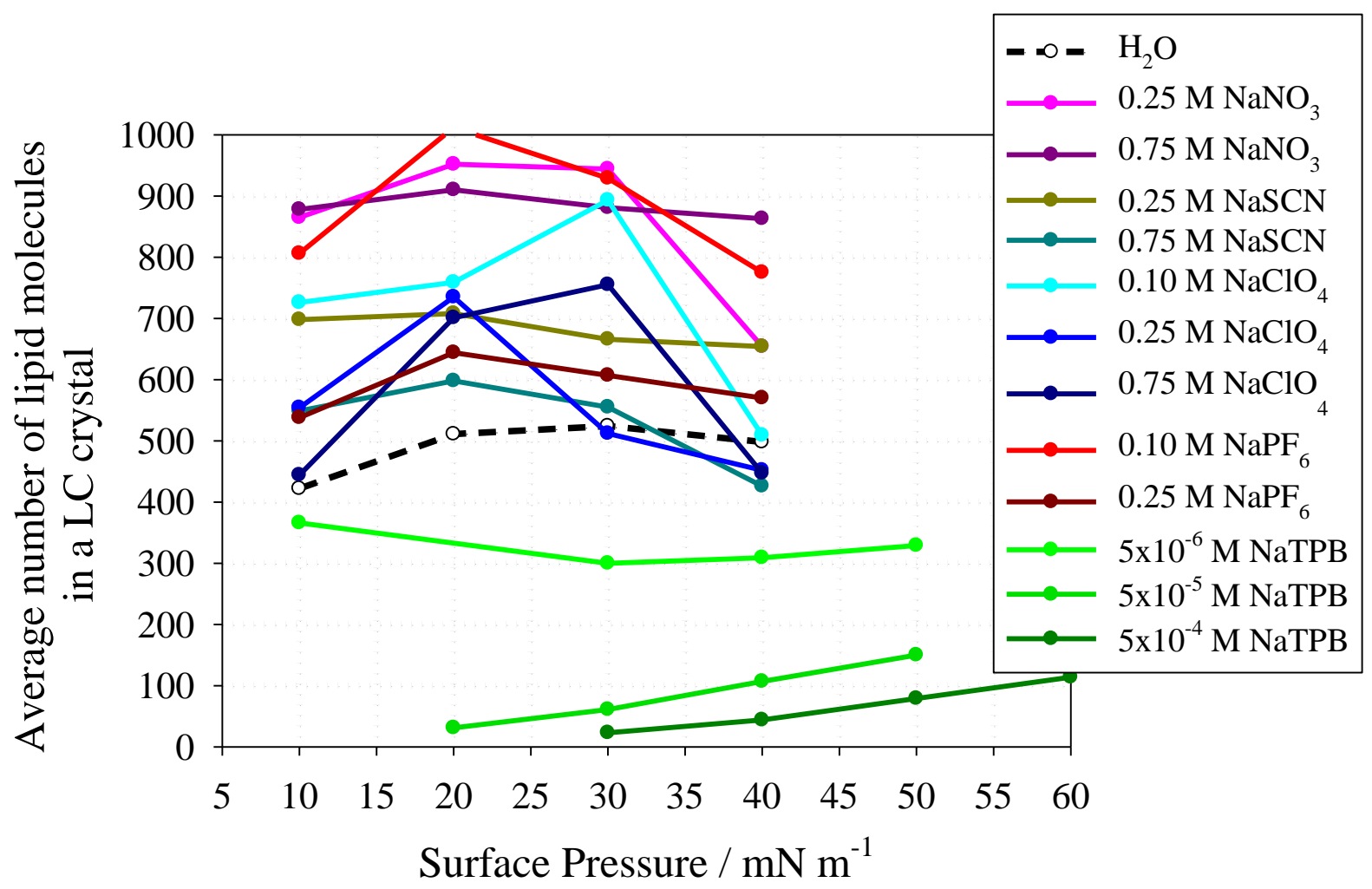

Figure 10: Average number of lipid molecules in a single crystalline domain of the LC phase of DPPC at $12{ }^{\circ} \mathrm{C}$, as a function of surface pressure, with salt concentration and type as a parameter. 
In the presence of most electrolytes the average crystal size increases (the statistical uncertainty of the crystal size is of the order of $\pm 100-150$ lipid molecules for large lipid domains, but may decrease to \pm 10 for smaller lipid domains). A drop of the crystal size at 40 $\mathrm{mN} \mathrm{m}^{-1}$, observed in many cases, may be a real effect. On the contrary, in the case of TPB the crystal size decreases substantially, an effect that is greatly enhanced at higher salt concentrations. This finding illustrates again the completely different mode of interaction of this large, hydrophobic ion with the lipid monolayers (mixed monolayer formation ${ }^{34-38}$ rather than intercalation within the LE phase ${ }^{1-5}$ ).

\subsection{How to quantitate anion-lipid interactions at low temperatures?}

In our previous work we had found that the effect of the salts on the surface pressure of the LE phase of DPPC at $22{ }^{\circ} \mathrm{C}$ can be understood on the basis of electrostatics (monolayer charging through ionic adsorption) alone. ${ }^{1-5}$ Quantification of ion-lipid interactions is possible at $22{ }^{\circ} \mathrm{C}$ by treating anion effects on the surface pressure of the LE phase. At $12{ }^{\circ} \mathrm{C}$ the situation is very different. There is no LE phase in the presence of water, but at high surface areas one obtains a mixture of a gas phase and a LC phase. The LE phase appears when salts are added, as illustrated in Figures 2-5. Any attempt to consider ionic adsorption to the monolayer must take into account this dramatic conformational/phase change. A systematic way to approach this problem is through the thermodynamic decomposition depicted in Figure S4 in the Supporting Information section. Preliminary calculations however show that this systematic approach does not work well, apparently because the DPPC monolayer structure changes continuously at $12{ }^{\circ} \mathrm{C}$ as a function of ion type and concentration. This is illustrated by the fact that the isotherms are not (even roughly) parallel to each other in the range of the LE phase (see Figure 2). To extract ion association parameters with DPPC monolayers at low temperatures one therefore needs very elaborate models, which will 
simultaneously take into account the anionic effects on monolayer structure (both at the single lipid and at the lipid assembly level) and electrostatics. Attempts towards such calculations have been presented in the past for lipid bilayers ${ }^{76-78}$ and can constitute a basis to address the present monolayer problem.

\section{Conclusions}

In this work we have considered the effects of anions of the lyotropic series on DPPC monolayers at $12{ }^{\circ} \mathrm{C}$. In the absence of salts the DPPC monolayer is quite ordered at this low temperature, but anion adsorption has a dramatic effect on the isotherm, counteracting the ordering effect of temperature. The condensed phase domains at zero pressure disappear and a LE-LC plateau reappears and shifts to higher pressures as the salt concentration in the subphase increases. The onset and intensity of this behavior are in agreement with the lyotropic series. A detailed investigation using isotherms, BAM, IRRAS and GIXD has revealed that ions impart disorder to the monolayer by intercalating into the LE phase, in analogy to their effects at higher temperatures. ${ }^{1-5}$ Much of the influence of anions can be understood in this way, most notably the monolayer expansion in the presence of salts, the changes in the $\mathrm{CH}_{2}$ vibrational frequencies of the lipid chains, and the larger tilt of the lipid molecules in the LC phase domains. There are a few aspects of the monolayer structure that are not significantly perturbed by the ions, such as the shape of the LC domains (as revealed by BAM), and the hydration of the carbonyl and phosphate groups (as revealed by IRRAS). The effects of anions are "extreme" on two aspects of the monolayer structure. One is that the ions lead to the reappearance of the LE-LC equilibrium, which is missing over pure water. A second effect is observed when large, hydrophobic anions, such as $\mathrm{PF}_{6}^{-}$or $\mathrm{TPB}$, are introduced. These ions, especially the latter, because of their large size and surface-active properties, presumably compete with lipids for the water surface, changing the headgroup 
orientation/hydration and forcing the lipids to adopt an untilted conformation in the crystals of the LC phase, a conformation hitherto seen only in rare cases in the case of DPPC, always using mixed monolayers with proteins or special water soluble compounds. This implies a dramatic perturbation of the phase structure of DPPC at low temperatures from the lipid point of view. From another standpoint this different behavior of very chaotropic anions may in fact indicate that we need to rethink about the lyotropic series. Until now chloride has been used as the rough dividing line between cosmotropes and chaotropes, implying that the "Hofmeister line" can be roughly divided into two regimes. ${ }^{6-18}$ The present results illustrate however that there exists one more "break" in the "Hofmeister line", which may be of particular importance in soft-matter systems. Large, very chaotropic anions are apparently capable of modifying the structure of soft-matter systems in dramatic ways, going beyond the systematic perturbation described by the lyotropic series. It will be very useful to examine in a systematic way the action of such ions on model systems such as lipid monolayers. A wealth of new effects can be anticipated in the presence of large hydrophobic anions, complex ions, or organic ions, which are potent enough to take part in the structure and organization of selfassembled soft-matter systems, and to create a link between the typical chaotropic anions and the biopolymers that take part in the organization of biological membranes.

\section{Acknowledgment}

Financial support for this work was provided by the Cyprus Research Promotion Foundation and the European Structural Funds for Cyprus under project ПENEK/ENI $\Sigma X / 0308 / 87$. We thank HASYLAB (DESY, Hamburg, Germany) for providing beam time and financial support for M.C. and E.L. under HASYLAB Project I-20090388 EC.

\section{Supporting Information available}


Figure S1 contains additional IRRAS spectra in the lipid carbonyl region. Figure S2 contains plots of the lattice distortion of the LC phase of DPPC and Figure S3 shows the compressibility of the DPPC monolayers as a function of salt type and concentration. Figure S4 shows a possible thermodynamic process for the quantification of anion-lipid interactions at $12{ }^{\circ} \mathrm{C}$. This material is available free of charge via the Internet at http://pubs.acs.org. 


\section{References}

(1) Aroti, A.; Leontidis, E.; Maltseva, E.; Brezesinski, G. J. Phys. Chem. B 2004, 108, $15238-15245$.

(2) Aroti, A.; Leontidis, E.; Dubois, M.; Zemb, T.; Brezesinski, G. Colloids Surf. A 2007, 303, 144-158.

(3) Leontidis, E.; Aroti, A.; Belloni, L. J. Phys. Chem. B 2009, 113, 1447-1459.

(4) Leontidis, E.; Aroti, A. J. Phys. Chem. B 2009, 113, 1460-1467.

(5) Viswanath, P.; Aroti, A.; Motschmann, H.; Leontidis, E. J. Phys. Chem. B 2009, 113, 14816-14823.

(6) Collins, K. D.; Washabaugh, M. W. Quart. Rev. Biophys. 1985, 18, 323-422.

(7) Cacace, M. G.; Landau, E. M.; Ramsden, J. J. Quart. Rev. Biophys. 1997, 30, 241-277.

(8) Baldwin, R. L. Biophys. J. 1996, 71, 2056-2063.

(9) Ninham, B. W.; Yaminsky, V., Langmuir 1997, 13, 2097-2108.

(10) Ninham, B. W. Adv. Colloid Int. Sci. 1999, 83, 1-17.

(11) Leontidis, E. Curr. Opin. Colloid Int. Sci. 2002, 7, 81-91.

(12) Kunz, W.; Lo Nostro, P.; Ninham, B. W. Curr. Opin. Colloid Int. Sci. 2004, 9, 1-18.

(13) Zhang, Y.; Cremer, P. S. Curr. Opin. Chem. Biol. 2006, 10, 658-663.

(14) Leontidis E., in Specific Ion Effects; Kunz, W., Ed.; World Scientific: Singapore, 2010; pp 55-84.

(15) Zhang, Y.; Cremer, P. S. Ann. Rev. Phys. Chem. 2010, 61, 63-83.

(16) Parsons, D. F.; Boström, M.; Lo Nostro, P.; Ninham, B. W. Phys. Chem. Chem. Phys. 2011, 13, 12352-12367.

(17) Ninham, B. W.; Lo Nostro, P. Molecular Forces and Self-Assembly; Cambridge Univ. Press: Cambridge, 2010.

(18) Lo Nostro, P. ; Ninham, B. W. Chem. Rev. 2012, 112, 2286-2322. 
(19) Ito, H.; Hellman Morton, T.; Vodyanoy, V. Thin Solid Films 1989, 180, 1-13.

(20) Yun, H.; Choi, Y.-W.; Kim, N. J.; Sohn, D. Bull. Korean Chem. Soc. 2003, 24, 377383.

(21) Frey, S. L.; Lee, K. Y. C. Langmuir 2007, 23, 2631-2637.

(22) Toimil, P.; Prieto, G.; Miñones, J. Jr, Sarmiento, F. Phys. Chem. Chem. Phys. 2010, $12,13323-13332$.

(23) Simon, S. A.; Lis, L. J.; Kauffman, J. W.; MacDonald, R. C. Biochim. Biophys. Acta $\mathbf{1 9 7 5}, 375,317-326$.

(24) Chapman, D.; Peel, W. E.; Kingston, B.; Lilley, T. H. Biochim. Biophys. Acta 1977, $464,260-275$.

(25) Sanderson, P. W.; Lis, L. J.; Quinn, P. J.; Williams, W. P. Biochim. Biophys. Acta 1991, 1067, 43-50.

(26) Bartucci, R.; Sportelli, L. Biochim. Biophys. Acta 1994, 1195, 229-236.

(27) Bartucci, R.; Belsito, S.; Sportelli, L. Chem. Phys. Lipids 1996, 79, 171-180.

(28) McIntosh, T. J. Biophys. J. 1980, 29, 237-246.

(29) Hauser, H.; Guyer, W.; Paltauf, F. Chem. Phys. Lipids 1981, 29, 103-120.

(30) Akutsu, H.; Seelig, J. Biochemistry 1981, 20, 7366-7373.

(31) Akutsu, H.; Nagamori, T. Biochemistry 1991, 30, 4510-4516.

(32) Macdonald, P. M.; Seelig, J. Biochemistry 1988, 27, 6769-6775.

(33) Rydall, J. R.; Macdonald, P. M. Biochemistry 1992, 31, 1092-1099.

(34) Shchipunov, Y. A.; Drachev, G. Y. J. Colloid Int. Sci. 1986, 110, 431-436.

(35) Matsumura, H.; Fukuma, M.; Furusawa, K. J. Colloid Int. Sci. 1985, 103, 561-568.

(36) Shapovalov, V.; Tronin, A. Langmuir 1997, 13, 4870-4876.

(37) Van Mau, N. D.; Issaurat, B.; Amblard, G. J. Colloid Int. Sci. 1984, 101, 1-9.

(38) Shapovalov, V. L. Thin Solid Films 1998, 327-329, 599-602. 
(39) Calero, C.; Faraudo, J. J. Am. Chem. Soc. 2011, 133, 15025-15035.

(40) Frahm, R.; Weigelt, J.; Meyer, G.; Materlik, G. Rev. Sci. Instrum. 1995, 66, $1677-$ 1680.

(41) Peterson, I. R.; Brezesinski, G.; Struth, B.; Scalas, E. J. Phys. Chem. B 1998, 102, 9437-9442.

(42) Flasiński, M.; Broniatowski, M.; Majewski, J.; Dynarowicz-Łątka, P. J. Colloid Int. Sci. 2010, 348, 511-521.

(43) Brezesinski, G.; Stefaniu, C.; Nandy, D.; Dutta Banik S.; Nandi, N., Vollhardt, D. J. Phys. Chem. C 2010, 114, 15695-15702.

(44) Kjaer, K.; Als-Nielsen, J.; Helm, C. A.; Tippman-Krayer, P.; Möhwald, H. J. Phys. Chem. 1989, 93, 3200-3206.

(45) Als-Nielsen, J.; Möhwald, H. In Handbook of Synchrotron Radiation, Vol. 4; S. Ebashi; M. Koch; E. Rubenstein, Eds.; North Holland: Amsterdam, 1991; pp 1-54.

(46) Kjaer, K. Physica B 1994, 198, 100-109.

(47) Als-Nielsen, J. ; Jacquermain, J. ; Kjaer, K. ; Lahav, M.; Leveiller, F. ; Leiserowitz, L. Phys. Rep. 1994, 246, 251.

(48) Kaganer, V. M.; Peterson, I. R.; Kenn, R. M.; Shih, M. C.; Durbin, M.; Dutta, P. J. Chem. Phys. 1995, 102, 9412-9422.

(49) Kaganer, V. M.; Möhwald, H.; Dutta, P. Rev. Mod. Phys. 1999, 71, 779-819.

(50) Buffeteau, T. ; Desbat, B.; Turlet, J. M. Appl. Spectrosc. 1991, 45, 380-389.

(51) Möhwald, H. Annu. Rev. Phys. Chem. 1990, 41, 441-476.

(52) Knobler, C. M. Adv. Chem. Phys. 1990, 77, 397-449.

(53) McConnell, H. M. Annu. Rev. Phys. Chem. 1991, 42, 171-195.

(54) Weidemann, G.; Vollhardt, D. Colloids Surf. A 1995, 101, 187-202.

(55) McConlogue, C. W.; Vanderlick, T. K. Langmuir 1997, 13, 7158. 
(56) Mitchell, M. L.; Dluhy, R. A. J. Am. Chem. Soc. 1988, 110, 712-718.

(57) Dluhy, R. A.; Wright, N. A.; Griffiths, P. R. Appl. Spectros. 1988, 42, 138-141.

(58) Hunt, R. D.; Mitchell, M. L.; Dluhy, R. A. J. Mol. Struct. 1989, 214, 93-109.

(59) Mendelsohn, R.; Flach, C. R. In Handbook of Vibrational Spectroscopy, Vol. 2; Chalmers, J. M., Griffiths, P. R., Eds.; J. Wiley and Sons: New York, 2002; pp 10281041.

(60) Mendelsohn, R.; Brauner, J.W; Gericke, A. Annu. Rev. Phys. Chem., 1995, 46, 305334.

(61) Okamura, E.; Umemura, J.; Takenaka, T. Biochim. Biophys. Acta 1985, 812, 139-146.

(62) Dicko, A.; Bourque, H.; Pézolet, M. Chem. Phys. Lipids 1998, 96, 125-139.

(63) Blume, A.; Hübner, W.; Messner, G. Biochemistry 1988, 27, 8239-8249.

(64) Lewis, R. N. A. H.; McElhaney, R. N.; Pohle, W.; Mantsch, H. H. Biophys. J. 1994, $67,2367-2375$

(65) Estrela-Lopis, I.; Brezesinski, G.; Möhwald, H. Biophys. J. 2001, 80, 749-754.

(66) Böhm, C.; Möhwald, H.; Leiserowitz, L.; Als-Nielsen, J.; Kjaer, K. Biophys. J. 1993, 64, 553-559.

(67) Brezesinski, G.; Dietrich, A.; Struth, B.; Böhm, C.; Bouwman, W. G.; Kjaer, K.; Möhwald, H. Chem. Phys. Lipids 1995, 76, 145-157.

(68) Wu, G.; Majewski, J.; Ege, C.; Kjaer, K.; Weygand, M. J.; Lee, K. Y. C. Biophys. J. 2005, 89, 3159-3173.

(69) Bringezu, F.; Dobner, B.; Brezesinski, G. Chem. Eur. Journal 2002, 8, 3203-3210.

(70) Zhai, X.; Brezesinski, G.; Möhwald, H.; Li, J. J. Phys. Chem. B 2004, 108, 1347513480.

(71) Wagner, K.; Brezesinski, G. Chem. Phys. Lipids 2007, 145, 119-127. 
(72) Brezesinski, G.; Müller, H.J.; Toca-Herrera, J.L.; Krustev, R. Chem. Phys. Lipids 2001, 110, 183-194.

(73) Lúcio, M.; Bringezu, F.; Reis, S.; Lima, J. L. F. C.; Brezesinski, G. Langmuir 2008, 24, 4132-4139.

(74) Dahmen-Levison, U.; Brezesinski, G.; Möhwald, H. Thin Solid Films 1998, 329, 616620.

(75) Brezesinski, G.; Thoma, M.; Struth, B.; Möhwald, H. J. Phys. Chem. 1996, 100, 31263130.

(76) Forsman, J. Langmuir 2006, 22, 2975-2978.

(77) Harries, D.; Podgornik, R.; Parsegian, V. A.; Mar-Or, E.; Andelman, D. J. Chem. Phys. 2006, 124, 224702.

(78) Mbamala, E. C.; Fahr, A.; May S. Langmuir 2006, 22, 5129-5136. 
Table 1. Lattice parameters, $a, b$ and $\gamma$, tilt angle $t$ with respect to the normal, in-plane unit cell area $\mathrm{A}_{\mathrm{xy}}$, and correlation lengths $\mathrm{L}_{\mathrm{xy}}$ and $\mathrm{L}_{\mathrm{z}}$ for DPPC monolayers over pure water and $\mathrm{NaClO}_{4}$ solutions at different surface pressures at $12{ }^{\circ} \mathrm{C}$. A distorted hexagonal lattice with NN tilt was assumed in all cases.

\begin{tabular}{cccccccccc}
\hline $\begin{array}{c}\mathrm{DPPC} \\
\text { on }\end{array}$ & $\begin{array}{c}\pi / \mathrm{mN} \\
\mathrm{m}^{-1}\end{array}$ & $\mathrm{a} / \AA$ & $\mathrm{b} / \AA$ & $\gamma /{ }^{\circ}$ & $\mathrm{t} /{ }^{\circ}$ & $\begin{array}{c}\mathrm{A}_{\mathrm{xy}} \\
/ \AA^{2}\end{array}$ & $\mathrm{~L}_{\mathrm{xy}}(11) / \AA$ & $\begin{array}{c}\mathrm{L}_{\mathrm{xy}}(02) \\
/ \AA\end{array}$ & $\begin{array}{c}\mathrm{L}_{\mathrm{z}} / \\
\AA\end{array}$ \\
\hline $\mathrm{H}_{2} \mathrm{O}$ & 10 & 5.752 & 5.183 & 123.7 & 35.2 & 24.8 & 83 & 321 & 18 \\
& 20 & 5.621 & 5.123 & 123.3 & 33.5 & 24.1 & 91 & 343 & 18 \\
& 30 & 5.393 & 5.049 & 122.3 & 28.4 & 23.0 & 83 & 369 & 19 \\
& 40 & 5.308 & 5.034 & 121.8 & 26.9 & 22.7 & 84 & 343 & 18 \\
$0.10 \mathrm{M}$ & 10 & 5.946 & 5.250 & 124.5 & 37.6 & 25.7 & 88 & 540 & 18 \\
$\mathrm{NaClO}_{4}$ & & & & & & & & & \\
& 20 & 5.779 & 5.189 & 123.8 & 35.5 & 24.9 & 100 & 481 & 18 \\
& 30 & 5.599 & 5.132 & 123.1 & 32.4 & 24.1 & 114 & 481 & 20 \\
& 40 & 5.442 & 5.064 & 122.5 & 29.8 & 23.2 & 69 & 436 & 19 \\
$0.25 \mathrm{M}$ & 10 & 5.995 & 5.264 & 124.7 & 38.0 & 25.9 & 76 & 481 & 18 \\
$\mathrm{NaClO}_{4}$ & & & & & & & & & \\
& 20 & 5.815 & 5.211 & 123.9 & 36.2 & 25.1 & 87 & 540 & 18 \\
& 30 & 5.589 & 5.117 & 123.7 & 32.3 & 23.9 & 91 & 343 & 18 \\
& 40 & 5.458 & 5.088 & 122.4 & 30.4 & 23.4 & 84 & 321 & 18 \\
$0.75 \mathrm{M}$ & 10 & 6.312 & 5.373 & 126.0 & 42.0 & 27.4 & 84 & 369 & 18 \\
$\mathrm{NaClO}_{4}$ & & & & & & & & & \\
& 20 & 6.073 & 5.294 & 125.0 & 39.8 & 26.3 & 87 & 540 & 19 \\
& 30 & 5.896 & 5.231 & 124.3 & 37.4 & 25.5 & 102 & 481 & 18 \\
& 40 & 5.735 & 5.176 & 123.6 & 35.3 & 24.7 & 82 & 343 & 18 \\
\hline
\end{tabular}


Table 2. Lattice parameters, $a, b$ and $\gamma$, tilt angle $t$ with respect to the normal, in-plane unit cell area $\mathrm{A}_{\mathrm{xy}}$, and correlation lengths $\mathrm{L}_{\mathrm{xy}}$ and $\mathrm{L}_{\mathrm{z}}$ for DPPC monolayers over $0.25 \mathrm{M}$ solutions of $\mathrm{NaNO}_{3}, \mathrm{NaSCN}$ and $\mathrm{NaPF}_{6}$ at different surface pressures at $12{ }^{\circ} \mathrm{C}$. A distorted hexagonal lattice with $\mathrm{NN}$ tilt was assumed in all cases. At $10 \mathrm{mN} \mathrm{m}{ }^{-1}$ over $0.25 \mathrm{M} \mathrm{NaPF}_{6}$ the monolayer is better described by an oblique lattice.

\begin{tabular}{cccccccccc}
\hline DPPC on & $\begin{array}{c}\pi / \mathrm{mN} \\
\mathrm{m}^{-1}\end{array}$ & $\mathrm{a} / \AA$ & $\mathrm{b} / \AA$ & $\gamma /{ }^{\circ}$ & $\mathrm{t} /{ }^{\circ}$ & $\begin{array}{c}\mathrm{A}_{\mathrm{xy}} \\
/ \AA^{2}\end{array}$ & $\begin{array}{c}\mathrm{L}_{\mathrm{xy}}(11) \\
/ \AA\end{array}$ & $\begin{array}{c}\mathrm{L}_{\mathrm{xy}}(02) \\
/ \AA\end{array}$ & $\begin{array}{c}\mathrm{L}_{z} / \\
\AA\end{array}$ \\
\hline $0.25 \mathrm{M}$ & 10 & 5.891 & 5.237 & 124.2 & 36.9 & 25.5 & 104 & 540 & 18 \\
$\mathrm{NaNO}_{3}$ & & & & & & & & & \\
& 20 & 5.683 & 5.164 & 123.4 & 34.5 & 24.5 & 110 & 540 & 18 \\
& 30 & 5.530 & 5.110 & 122.8 & 31.6 & 23.8 & 119 & 481 & 19 \\
& 40 & 5.385 & 5.061 & 122.1 & 28.7 & 23.1 & 80 & 481 & 20 \\
$0.25 \mathrm{M}$ & 10 & 5.940 & 5.248 & 124.5 & 37.8 & 25.7 & 95 & 481 & 18 \\
$\mathrm{NaSCN}$ & & & & & & & & & \\
& 20 & 5.756 & 5.187 & 123.7 & 35.2 & 24.8 & 93 & 481 & 18 \\
& 30 & 5.568 & 5.116 & 123.0 & 31.8 & 23.9 & 93 & 436 & 18 \\
& 40 & 5.440 & 5.076 & 122.4 & 29.4 & 23.3 & 71 & 302 & 19 \\
$0.25 \mathrm{M}$ & 10 & 5.918 & 5.178, & 125.3 & 37.6 & 25.5 & 95 & 368 & 21 \\
$\mathrm{NaPF}_{6}$ & & & 5.288 & & & & & & \\
& 20 & 5.665 & 5.132 & 123.5 & 34.1 & 24.2 & 91 & 436 & 20 \\
& 30 & 5.196 & 4.965 & 121.6 & 23.7 & 22.0 & 106 & 321 & 19 \\
& 40 & 5.124 & 4.922 & 121.4 & 21.8 & 21.5 & 122 & 256 & 18 \\
\hline
\end{tabular}


TOC graphic image

Chaotropic salts Structure-disrupting salts

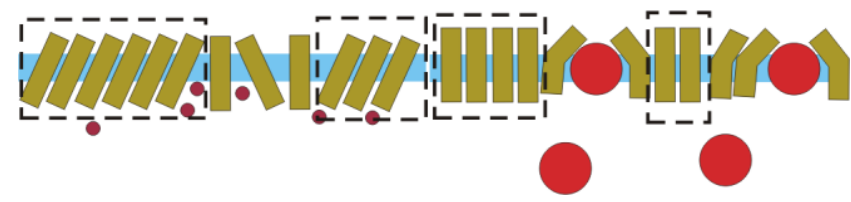

